\title{
Occult Blood Measurement
}

National Cancer Institute

\section{Source}

National Cancer Institute. Occult Blood Measurement. NCI Thesaurus. Code C74686.

A measurement of the blood in body products such as a urine or stool sample, not detectable on gross examination. 